\title{
Vector Competence of Ixodes scapularis and Ixodes ricinus (Acari: Ixodidae) for Three Genospecies of Borrelia burgdorferi
}

\author{
MARC C. DOLAN, ${ }^{1}$ JOSEPH PIESMAN, ${ }^{1}$ M. LAMINE MBOW, ${ }^{1}$ GARY O. MAUPIN, ${ }^{1}$ \\ OLIVIER PÉTER, ${ }^{2}$ MICHEL BROSSARD, ${ }^{3}$ AND WILLIAM T. GOLDE ${ }^{1}$
}

\begin{abstract}
J. Med. Entomol. 35(4): 465-470 (1998)
ABSTRACT The vector competence of 2 tick species, Ixodes ricinus (L.) and Ixodes scapularis Say, was determined and compared for 3 genospecies of Borrelia burgdorferi. The 3 genospecies of $B$. burgdorferi used in the following experiments were Borrelia burgdorferi sensu stricto (B-31 and B-31.D1 clone), Borrelia afzelii (strain Pgau.C3), and Borrelia garinii (strain VS286 and VSBP). Spirochetes from all 5 strains were inoculated intradermally into outbred mice; larval ticks of both species were subsequently fed on those mice and replete larvae were assayed for infection by culture in BSK-H media every $7 \mathrm{~d}$ for $4 \mathrm{wk}$. Infection frequencies in I. scapularis exposed to the 5 strains were as follows: B-31 (90\%), B-31.D1 (83\%), Pgau.C3 (87\%), VS286 (10\%), and VSBP (5\%). The comparable infection frequencies for I. ricinus were B-31 (3\%), B-31.D1 (3\%), Pgau.C3 (90\%), VS286 (5\%), and VSBP (3\%). Resultant nymphal I. scapularis successfully transmitted B-31, B-31.D1, Pgau.C3, and VS286 to outbred mice. I. ricinus nymphs transmitted Pgau.C3 and VS286. Both species failed to transmit strain VSBP.
\end{abstract}

KEY WORDS Ixodes ricinus, Ixodes scapularis, Borrelia burgdorferi, vector competence

LYME DISEASE Is the most common human vector-borne disease in the United States and Europe (Strle and Stantic-Pavlinic 1996, Dennis 1995). The Lyme disease spirochete Borrelia burgdorferi sensu lato is maintained in zoonotic cycles involving primarily small rodent hosts and is transmitted by ticks of the genus Ixode's (Lane et al. 1991). The primary vector of Lyme disease in North America is Ixodes scapularis Say; $I x$ odes ricinus (L.) serves as the primary vector in Europe (Burgdorfer et al. 1983). The principal vector of the Lyme disease spirochete in Asia is Ixodes persulcatus (Schulze) (Takada et al. 1994). Laboratory colonies of $I$. scapularis infected with B. burgdorferi have been produced in natural zoonotic cycles between tick and rodent (Piesman 1993). The standard procedure for maintaining high prevalence of infection in these colonies involves exposing rodents to infected nymphs, and subsequently feeding colony larvae on these naturally infected rodents. These practices routinely result in the production of large numbers of infected nymphal $I$. scapularis. In contrast, infection of laboratory $I$. ricinus with $B$. burgdorferi has been achieved mainly through artificial means involving

\footnotetext{
${ }^{1}$ Division of Vector-Borne Infectious Diseases, National Centers for Infectious Diseases, Centers for Disease Control and Prevention, Public Health Service, U.S. Department of Health and Human Services, P.O. Box 2087, Fort Collins, CO 80522.

2 Institut Central des Hôpitaux Valaisans. P.O. Box 510, CH-1950 Sion, Switzerland.

'3 Institute de Zoology', Université de Neuchâtel, 2007 Neuchâtel, Switzerland. Division of Vector-Borne Infectious Diseases, National Center for Infectious Diseases, Centers for Disease Control and Prevention, U.S. Department of Health and Human Services P.O. Box 2087, Fort Collins, CO 80522
}

capillary feeding of spirochetes in BSK-H medium, and exposing mice to these infected nymphs (Hu et al. 1992; Gern et al. 1993, 1994; Kurtenbach et al. 1994).

A great deal of genetic diversity exists within $B$. burgdorferi sensu lato (Postic et al. 1994, Fukunaga et al. 1996, Mathiesen et al. 1997). Only 3 genospecies, however, are associated with human Lyme disease: $B$. burgdorferi sensu stricto, Borrelia afzelii, and Borrelia garinii (Baranton et al. 1992, Canica et al. 1993, Anthonissen et al. 1994). These 3 genospecies exist concomitantly in endemic areas of Europe (Nohlmans et al. 1995, Péter et al. 1995, Strle et al. 1995). The search for a Lyme disease vaccine has focused primarily on the outer surface protein (OspA) as the test antigen (Fikrig et al. 1990, Gern et al. 1994, Golde et al. 1995). Unfortunately, the 3 disease-causing genospecies of $B$. burgdorferi exhibit variation in their OspA proteins (Péter and Bretz 1992, Marconi et al. 1993). A vaccine consisting of the OspA protein from 1 genospecies may not protect against all 3 genospecies (Schaible et al. 1993, Lovrich et al. 1993). Therefore, a multivalent OspA vaccine may be essential in Europe to protect against Lyme disease (Gern et al. 1997).

OspA vaccines appear to work by killing spirochetes in the vector tick before these spirochetes have a chance to migrate from the tick midgut and switch the predominant Osp from OspA to OspC (Fikrig et al. 1992, Schwan et al. 1995, de Silva et al. 1996). Thus, evaluation of vaccine efficacy should be assessed using tick transmission (Fikrig et al. 1995). Moreover, ticks infected with each of the 3 genospecies would allow for a heterologous tick challenge to assess comprehensively protection afforded by candidate antigens. 
Accordingly, as a prelude to multivalent vaccine trials, we infected laboratory colonies of $I$. scapularis and $I$. ricinus, with all 3 genospecies of $B$. burgdorferi.

\section{Materials and Methods}

Tick Colonies. Larval I. scapularis used in these experiments came from adult ticks flagged in Westchester County, NY, in 1994 (WC '94); this colony was highly susceptible to $B$. burgdorferi and free of transovarially acquired spirochetes (Piesman et al. 1996). Colony I. ricinus were derived from nymphal and adult ticks flagged in Neuchâtel, Switzerland, during the first $2 \mathrm{wk}$ of June 1994. These I. ricinus ticks were shipped to the Centers for Disease Control and Prevention (CDC), Division of Vector-Borne Infectious Diseases, Fort Collins, CO, for the purpose of establishing a laboratory colony. All ticks were held at $21^{\circ} \mathrm{C}, 97 \% \mathrm{RH}$, and a photoperiod of $16: 8$ (L:D) h. Twenty-five field-collected adult female $I$. ricinus (along with 20 males) fed on a rabbit. A total of 3 adult females oviposited and derived larvae was included in the colony. Approximately $1 / 4$ of each resultant $F_{1}$ larval batch was surface sterilized and cultured in BSK-H media as unfed larvae; all these $\mathrm{F}_{1}$ larvae were negative on culture. An ear biopsy was performed on the rabbit exposed to the adult ticks; this culture was negative. In addition, 275 field-collected $I$. ricinus nymphs were fed on a total of 8 ICR outbred mice from a specific pathogen-free colony maintained at the $\mathrm{Di}$ vision of Vector-Borne Infectious Diseases, CDC, Fort Collins, CO; 255 replete nymphs were collected. All 8 of these mice were ear biopsy culture positive (Sinsky and Piesman 1989); the mice were determined to be infected with $B$. afzelii by pulsed-field gel electrophoresis (PFGE) of all isolates (data not shown). Replete nymphs were allowed to molt to adults and fed on the ears of a rabbit. Skin from the rabbit's ear was cultured and proved negative for spirochetes. Twenty-five adult females derived from these fieldcollected nymphs were fed on a rabbit. Twelve fed to repletion and oviposited, and their resultant $F_{1}$ larvae were added to the colony. Again, $\approx 1 / 4$ of flat $F_{1}$ larvae were cultured in BSK-H media. None of these larvae produced spirochetes. Approximately 3,000 unfed $F_{1}$ larval $I$. ricinus were cultured in the course of establishing this colony; none produced spirochetes on culture.

Spirochete Strains. Three genospecies of B. burgdorferi consisting of 5 different isolates were used as follows: VS286 ( $B$. garinii tick isolate [Péter et al. 1995]), VSBP (B. garinii human isolate [provided by O. Péter]), Pgau.C3 (B. afzelii; a cloned derivative of Pgau [Wilske et al. 1988]), B-3l (passage 6, provided by Alan Barbour, University of California, Irvine; strain originally isolated from Shelter Island, NY [Burgdorfer et al. 1982]), and B-31.D1 (B-31 clone). The European strains were both characterized and typed by using the monoclonal antibody D6 and genetic analysis as previously described (Péter et al. 1995, Péter et al. 1998).

Mouse Inoculations. Groups of 3 ICR outbred mice were inoculated with each of the 5 Borrelia isolates.
Borrelia were grown in BSK-H media and $\approx 1 \times 10^{5}$ spirochetes were inoculated intradermally into each mouse. Mice were assayed for infection at $21 \mathrm{~d}$ after inoculation by ear biopsy (Sinsky and Piesman $1989) ; 14$ of 15 mice were ear biopsy culture positive. The 1 negative mouse (exposed to B-31) was excluded from the study. Animals were handled according to procedures outlined in a protocol on file with the animal care and use committee at the Division of Vector-Borne Infectious Diseases, CDC, Fort Collins, CO.

Tick Infestations and Culture. Approximately 250 uninfected larval I. ricinus and I. scapularis were placed separately on ear biopsy positive mice, day 28 after inoculation, from each of the 5 groups and allowed to feed to repletion. Ten replete larvae of each tick species that had fed on mice infected with each of the 5 strains were surface sterilized and cultured in BSK-H media. Surface sterilization consisted of a 3-min soak in hydrogen peroxide, followed by a $10-\mathrm{min}$ soak in $70 \% \mathrm{EtOH}$. Ticks were then transferred to $4-\mathrm{ml}$ glass tissue grinders and triturated in $0.5 \mathrm{ml}$ of BSK-H culture medium (Pollack et al. 1993) containing 6\% rabbit serum and antibiotics (rifampin, $50 \mu \mathrm{g} / \mathrm{ml}$; cycloheximide, $200 \mu \mathrm{g} / \mathrm{ml}$; phosphomycin, $200 \mu \mathrm{g} / \mathrm{ml}$; and fungizone, $2.5 \mu \mathrm{g} / \mathrm{ml}$ ). The mixture was decanted into 4-ml tubes containing BSK-H medium and incubated at $34^{\circ} \mathrm{C}$. These procedures were performed at zero, $7,14,21$, and $28 \mathrm{~d}$ after repletion. Cultures were examined for spirochetes as previously described (Dolan et al. 1997).

Upon molting (44-60 d after repletion), 20 resultant nymphs of each tick species from each infected mouse were cultured to assay for transstadial infection. Cultures were read by dark-field microscopy every $7 \mathrm{~d}$ for $4 \mathrm{wk}$. Remaining nymphs were both individually fed and group fed on clean ICR outbred mice, to test for spirochete transmission to a subsequent host. Although I. scapularis nymphs were placed directly on mice, I. ricinus nymphs were placed in a feeding capsule attached to the mouse as previously described (Mbow et al. 1994). Capsules were required for I. ricinus nymphal feeding, because these ticks attach to mice less readily than do I. scapularis. Mice were assayed for infection $28 \mathrm{~d}$ after nymphal drop-off by ear biopsy (Sinsky and Piesman 1989). Again cultures were read every $7 \mathrm{~d}$ for $4 \mathrm{wk}$.

Xenodiagnosis of Tick-Infected Mice. In an additional attempt to produce $B$. garinii-infected nymphs, 1 of the mice that tested ear biopsy positive after being fed on by $B$. garinii-infected $I$. ricinus nymphs, received a subsequent infestation of $I$. ricinus larvae. These mice were exposed to larvae at $5 \mathrm{wk}$ after exposure to nymphs. Resultant, engorged larvae were assayed for infection by culture at $2 \mathrm{wk}$ after feeding; cultures were examined weekly for spirochetes by dark-field microscopy for $4 \mathrm{wk}$.

\section{Results}

Ixodes ricinus. Larval I. ricinus demonstrated the ability to acquire all 3 genospecies of Borrelia (Table 
'Table 1. Ability of larval $I$, ricinus and $I$, scapularis to acquire and maintain 5 strains of B. burgdorferi (B. b.)

\begin{tabular}{|c|c|c|c|c|c|c|}
\hline \multirow{3}{*}{$\begin{array}{c}\text { Tick species and } \\
\text { strain of } B . b .\end{array}$} & \multicolumn{5}{|c|}{ No. infected/no. examined } & \multirow{3}{*}{ Total $(\%)$} \\
\hline & \multicolumn{5}{|c|}{ Days after repletion } & \\
\hline & 7 & 14 & 21 & 28 & $\geq 44^{a}$ & \\
\hline \multicolumn{7}{|l|}{ I. ricints } \\
\hline B. $a f z t^{\prime} l i i$ & $8 / 10$ & $9 / 10$ & $10 / 10$ & $9 / 10$ & $18 / 20$ & $54 / 60(90)$ \\
\hline B. garinii (VS286) & $0 / 10$ & $1 / 10$ & $0 / 10$ & $2 / 10$ & $0 / 20$ & $3 / 60(5)$ \\
\hline B. garinii (VSBP) & $1 / 10$ & $1 / 10$ & $0 / 10$ & $0 / 10$ & $0 / 20$ & $2 / 60(3)$ \\
\hline B-31 (passage 6) & $1 / 10$ & $1 / 10$ & $0 / 10$ & $0 / 10$ & $0 / 20$ & $2 / 60(3)$ \\
\hline B-31.D1 (clone) & $0 / 10$ & $2 / 10$ & $0 / 10$ & $0 / 10$ & $0 / 20$ & $2 / 60(3)$ \\
\hline \multicolumn{7}{|l|}{ I. scapularis } \\
\hline B. afzelii & $10 / 10$ & $8 / 10$ & $9 / 10$ & $8 / 10$ & $17 / 20$ & $52 / 60(87)$ \\
\hline B. garinii (VS286) & $1 / 10$ & $1 / 10$ & $2 / 10$ & $2 / 10$ & $0 / 20$ & $6 / 60(10)$ \\
\hline B. garinii (VSBP) & $1 / 10$ & $0 / 10$ & $2 / 10$ & $0 / 10$ & $0 / 20$ & $3 / 60(5)$ \\
\hline B-31 (passage 6) & $9 / 10$ & $8 / 10$ & $9 / 10$ & $10 / 10$ & $18 / 20$ & $54 / 60(90)$ \\
\hline B-31.DI (clone) & $8 / 10$ & $8 / 10$ & $7 / 10$ & $9 / 10$ & $18 / 20$ & $50 / 60(83)$ \\
\hline
\end{tabular}

"After molting to nymphs (44-60 d after repletion).

1). Only B. afielii, however, demonstrated efficient transstadial survival to resultant nymphs. Overall infection frequencies of $I$. ricinus for $B$. burgdorferi sensu stricto (B-31 low), B. burgdorferi sensu stricto (B31.D1 clone), B. afzelii (Pgau.C3), B. garinii (VS286), and $B$. garinii (VSBP) were $3,3,90,5$, and $3 \%$, respectively.

Resultant nymphs from 3 of the 5 groups were allowed to feed on naive ICR outbred mice. A range of 10-30 nymphal ticks was fed on each mouse. Resultant nymphs that had fed on mice infected with $B$. burgdorferi sensu stricto were not fed on naive ICR outbred mice because of low infection rates and the small numbers of these ticks that were available. Nymphal ticks were able to transmit 1 of 2 B. garinii isolates (VS286) and B. afzelii (Pgau.C3) (Table 2). Nymphal I. ricinus did not successfully transmit VSBP (B. garinii), an isolate originally made from human CSF.

One of the ICR outbred mice that had been naturally infected by being fed on by $B$. garinii (VS286)infected $I$. ricinus nymphs was exposed to uninfected I. ricinus larvae. Larvae were allowed to feed ad libi-

Table 2. Albility of $I$. ricimus nymphs to transmit 3 strains of $B$. burgalorferi (B. b.)

\begin{tabular}{rlcc}
\hline \hline Trial & Strain of B. $b$. & $\begin{array}{c}\text { No. of nymphs fed } \\
\text { on mouse }\end{array}$ & $\begin{array}{c}\text { Ear biopsy } \\
\text { result }\end{array}$ \\
\hline 1 & B. affclii & 14 & + \\
2 & B. afzelii & 25 & + \\
3 & B. af zelii & 17 & + \\
4 & B. garinii (VS286) & 9 & - \\
5 & B. garinii (VS286) & 23 & - \\
6 & B. garinii (VS286) & 18 & + \\
7 & B. garinii (VS286) & 24 & - \\
8 & B. garinii (VS286) & 26 & - \\
9 & B. garinii (VS286) & 20 & + \\
10 & B. garinii (VS2S6) & 21 & - \\
11 & B. garinii (VS286) & 19 & - \\
12 & B. garinii (VS286) & 25 & - \\
13 & B. garinii (VSBP) & 26 & - \\
14 & B. garinii (VSBP) & 27 & - \\
15 & B. garinii (VSBP) & 21 & \\
\hline
\end{tabular}

Transmission experiments were not conducted with B-31 and B-31.DI due to small numbers of infected nymphs available. tum, collected, and reassayed for infection by culture; 6 of 20 replete larvae (30\%) cultured were positive. A 10 -fold increase resulted from feeding larvae on mice infected with VS 286 by tick-bite compared with larvae feeding on needle-inoculated animals.

Ixodes scapularis. Larval I. scapularis were fed on mice infected with $B$. burgdorferi sensu stricto (B-31. low), B. burgdorferi sensu stricto (B-31.D1), B. afzelii (Pgau.C3), B. garinii (VS286), and B. garinii (VSBP). Replete larvae were cultured as mentioned above. Overall infection frequencies for the 5 aforementioned isolates were $90,83,87,10$, and $5 \%$, respectively. Resultant nymphs were fed on naive ICR outbred mice. I. scapularis was vector competent for 4 of the 5 spirochete isolates. The success of transmission to a subsequent host (Table 3) was $100 \%$ for B. burgdorferi sensu stricto (B-31 low), B. burgdorferi sensu stricto (B-31.Dl clone), B. afzelii (Pgau.C3), and 25\% for B. garinii (VS286). I. scapularis was unable to transmit the human isolate (VSBP) of $B$. garinii to naive ICR outbred mice.

\section{Discussion}

In the current study we successfully infected $I$. ricinus and $I$. scapularis with all 3 genospecies of $B$.

Table 3. Ability of I. scapularis nymphs to transmit 5 strains of $B$. burgdorferi (B. b.)

\begin{tabular}{rlcc}
\hline \hline Trial & Strain of $B . b$. & $\begin{array}{c}\text { No. of nymphs fed } \\
\text { on mouse }\end{array}$ & $\begin{array}{c}\text { Ear biopsy } \\
\text { result }\end{array}$ \\
\hline 1 & B. afzelii & 7 & + \\
2 & B. afzelii & 16 & + \\
3 & B. garinii (VS286) & 14 & + \\
4 & B. garinii (VS286) & 12 & - \\
5 & B. garinii (VS286) & 24 & - \\
6 & B. garinii (VS286) & 21 & - \\
7 & B. garinii (VSBP) & 15 & - \\
8 & B. garinii (VSBP) & 11 & - \\
9 & B. garinii (VSBP) & 23 & - \\
10 & B. garinii (VSBP) & 21 & + \\
11 & B-31 (passage 6) & 10 & + \\
12 & B-31 (passage 6) & 6 & + \\
13 & B-3l.D1 (clone) & 8 & + \\
14 & B-31.D1 (clone) & 7 & \\
\hline
\end{tabular}


burgdorferi. This was accomplished by the natural route of feeding larvae on infected mice. In contrast, most experiments employing infected I. ricinus nymphs used ticks infected by artificial means. Gern et al. (1994), Hu et al. (1992), and Kurtenbach et al. (1994) reported using I. ricinus nymphs infected by capillary feeding BSK-H medium containing spirochetes. Although effective, this method seems to be more time-consuming and less efficient than acquiring spirochetes naturally by feeding on an infected host. Moreover, dispersal of spirochetes within artificially infected ticks may differ from that within naturally infected ones. Allowing ticks to become infected by feeding on mice also mimics what occurs in nature. Mice infected by tick-bite are more infectious than needle-inoculated mice. Gern et al. (1993) reported that mice infected by the natural route with infected I. ricinus ticks were substantially more infective for ticks by 2- to 6 -fold than mice experimentally inoculated. Piesman (1993) reported similar findings in $I$. scapularis. Our work determined that rodents infected via tick feeding or inoculated with tick homogenates were more infectious to ticks than rodents infected with cultured spirochetes. In the current study a 10fold increase occurred in the infection frequency of larval $I$. ricinus when they were allowed to fed on naturally infected mice as compared with needleinfected mice.

OspA vaccines act by preventing spirochetes from leaving the tick midgut and migrating to the salivary glands prior to transmission to the host (Fikrig et al. 1992, de Silva et al. 1996), suggesting that a valid test of a vaccine candidate antigen requires a natural tick challenge. In addition, the observation that a given OspA antigen derived from 1 genospecies may not protect against all 3 disease-causing genospecies of $B$. burgdorferi (Schaible et al. 1993, Lovrich et al. 1993) requires that ticks infected with each genospecies be available to test a multivalent vaccine. Most vaccine trials have used ticks infected in the laboratory with only B. burgdorferi sensu stricto (Gern et al. 1994, Golde et al. 1995). One vaccine trial used a combination of ticks collected in the field in the northeast United States, California, Sweden, and Germany, as well as ticks exposed to characterized strains (Fikrig et al. 1995). Fikrig et al. (1995) showed that a single antigen produced from the OspA gene derived from $B$. burgdorferi sensu stricto could afford protection against both $B$. burgdorferi sensu stricto and $B$. afzelii. These researchers failed, however, to infect rodents with $B$. garinii-infected ticks. The current study should facilitate efforts to produce $B$. garinii-infected ticks, enabling vaccine candidates to be tested against ticks infected with each of the 3 disease-producing genospecies of B. burgdorferi (Gern et al. 1997).

The principal reservoir hosts for $B$. burgdorferi sensu stricto and B. afzelii are clearly rodents. In the northeastern United States, the white-footed mouse, Peromyscus leucopus, is the primary reservoir of $B$. burgdorferi sensu stricto (Mather et al. 1989); in the Rocky Mountains, the Mexican woodrat, Neotoma mexicana, is the primary reservoir (Maupin et al.
1994), and the dusky-footed woodrat, Neotoma fuscipes, and the California kangaroo rat, Dipodomys heermanni, serve as primary reservoirs in the Pacific Northwest (Brown and Lane 1992). In Europe (Humair et al. 1995) and in Japan (Nakao and Miyamoto 1995) Borrelia isolates from rodents appear to be principally B. afzelii. Humair et al. (1995) reported a specific association exists between $B$. afzelii and rodent reservoirs in Europe.

Our research shows the $I$. ricinus used in these experiments to be most susceptible to B. afzelii. I. ricinus collected in the field used to start the laboratory colony were fed on New Zealand white rabbits and ICR outbred mice. Cultured ear biopsies from the mice yielded $8 \mathrm{~B}$. afzelii isolates. According to $\mathrm{Hu}$ et al. (1992), B. burgdorferi sensu stricto is the predominant genospecies in the area where the $I$. ricinus ticks were collected, followed by B. afzelii. Strle et al. (1995) reported isolating $B$. afzelii only from rodents in 3 of 6 sites studied in Slovenia. Moreover, Humair et al. (1995) reported isolating only 1 genospecies, $B$. afzelii, from rodent ears in 2 Lyme disease-endemic areas of Switzerland, despite isolating all 3 genospecies from the ticks in the same 2 areas. Their findings of heterogeneity of tick isolates and homogeneity of rodent isolates suggests that an affinity exists between $B$. afzelii and rodents, and indicates other genospecies may be associated with other vertebrate hosts.

Several studies have demonstrated that both $I$. ricinus and I. scapularis frequently parasitize and acquire Borrelia infections from birds (Magnarelli et al. 1992, Battaly and Fish 1993, Humair et al. 1993, Isogai et al. 1994, Stafford et al. 1995, Piesman et al. 1996). Mehl and Traavik (1983) demonstrated I. uriae associated with seabird colonies. Olsen et al. (1995) found seabirds infected with Borrelia. Sequence analysis revealed DNA obtained was from $B$. garinii. The relatively low body temperature of $38^{\circ} \mathrm{C}$ in certain seabirds compared with the body temperature of terrestial birds $\left(40^{\circ} \mathrm{C}\right)$ suggests seabirds may be competent hosts for Borrelia spirochetes (Olsen et al. 1995, Piesman et al. 1996). These findings suggest birds may play an important role as reservoirs for Borrelia, particularly $B$. garinii. That $B$. garinii is associated with nonrodent hosts may explain the difficulty of getting $B$. garinii into a mouse model. Our research, however, shows that it is possible to infect $I$. ricinus and $I$. scapularis with $B$. garinii by feeding larvae on naturally infected mice.

Assessment of protection in mice, using the natural vector, requires infected ticks. One could consider using field-collected ticks; however, the risk involved is the potential transmission of other pathogens. Ticks are excellent vectors of disease-producing agents and can be simultaneously infected with pathogens other than B. burgdorferi such as Babesia microti, human granulocytic ehrlichiosis, and tick-borne encephalitis. Laboratory-reared colonies can be generated and maintained free of pathogens other than B. burgdorferi (Piesman et al. 1986, Telford et al. 1996, Benda 1958). In addition, vaccines that induce anti-tick immunity may act against a broad array of tick-borne pathogens 
simultaneously (Wikel et al. 1997). Therefore, the need for infected ticks to test the efficacy of anti-tick vaccines and vaccines against various etiologic agents is essential.

\section{Acknowledgments}

We thank Jeremy S. Gray and Joseph E. Dolan for reviewing the manuscript and Christine $M$. Happ for help with preparing tables. This research was funded in part by a Cooperative Research and Development Agreement between Pfizer Animal Health and the Center for Disease Control and Prevention, Division of Vector-Borne Infectious Diseases, Lyme Disease Vector Section, Fort Collins, CO.

\section{References Cited}

Anthonissen, F. M., M. DeKesel, P. P. Hoet, and G. H. Bigaignom. 1994. Evidence for involvement of different genospecies of Borrelia in the clinical outcome of Lyme disease in Belgium. Res. Microbiol. 145: 327-331.

Baranton, G., D. Postic, I. Saint Girons, P. Boerlin, J. C. Piffaretti, M. Assous, and P.A.D. Grimont. 1992. Delineation of Borrelia burgdorferi sensu stricto, Borrelia garinii sp. nov, and group VS461 associated with Lyme borreliosis. Int. J. Syst. Bateriol. 42: 378-383.

Battaly, G. R., and D. Fish. 1993. Relative importance of bird species as hosts for immature Ixodes dammini (Acari: Lxodidae) in a suburban residential landscape of southern New York State. J. Med. Entomol. 30: 740-747.

Benda, R. 1958. The common tick Ixodes ricinus (L.) as a reservoir and vector of tick-borne encephalitis. I. Survival of the virus (strain B3) during the development of the tick under laboratory conditions. J. Hyg. Epidemiol. 2: 314.

Brown, R. N., and R. S. Lane. 1992. Lyme disease in California: a novel enzootic transmission cycle of Borrelia burgdorferi. Science (Wash. D.C.) 256: 1439-1442.

Burgdorfer, W., A. G. Barbour, S. G. Hayes, J. L. Benach, E. Grunwaldt, and J. P. Davis. 1982. Lyme disease-a tickborne spirochetosis? Science (Wash. D.C.) 216: 13171319.

Burgdorfer, W., A. G. Barbour, S. F. Hayes, O. Péter, and A. Aeschlimann. 1983. Erythema chronicum migrans-a tick-borne spirochetosis. Acta. Trop. 40: 79-83.

Canica, M. M., F. Nato, L. du Merle, J. C. Mazie, G. Baranton, and D. Postic. 1993. Monoclonal antibodies for identifcation of Borrelia afzelii sp. nov. associated with late cutaneous manifestations of Lyme borreliosis. J. Infect. Dis. 25: $441-448$.

Dennis, D. T. 1995. Lyme disease. Dermatol. Clin. 13: 537551.

De Silva, A. M., S. R. Telford III, L. R. Brunet, S. W. Barthold, and E. Fikrig. 1996. Borrelia burgdorferi OspA is an arthropod-specific transmission-blocking Lyme disease vaccine. J. Exp. Med. 183: 271-275.

Dolan, M. C., G. O. Maupin, N. A. Panella, W. T. Golde, and J. Piesman. 1997. Vector competence of Ixodes scapularis, I. spinipalpis, and Dermacentor andersoni (Acari: Ixodidae) in transmitting Borrelia burgdorferi, the etiologic agent of Lyme disease. J. Med. Entomol. 34: 128-135.

Fikrig, E., S. W. Barthold, F. S. Kantor, and R. A. Flavell. 1990. Protection of mice against the Lyme disease agent by immunizing with recombinant OspA. Science (Wash. D.C.). 250: $553-556$.

Fikrig, E., S. R. Telford III, S. W. Barthold, F. S. Kantor, A. Spielman, and R. A. Flavell. 1992. Elimination of Borre- lia burgdorferi from vector ticks feeding on OspA-immunized mice. Proc. Natl. Acad. Sci. U.S.A. 89: 5418-5421.

Fikrig, E., S. R. Telford III, R. Wallich, M. Chen, Y. Lobet, F. R. Matuschka, R. B. Kimsey, F. S. Kantor, S. W. Barthold, A. Spielman, and R. A. Flavell. 1995. Vaccination against Lyme disease caused by diverse Borrelia burgdorferi. J. Exp. Med. 181: 215-221.

Fukunaga, M. A. Hamase, K. Okada, and M. Nakao. 1996. Borrelia tanukii sp. nov. and Borrelia turdae sp. nov. found from Ixodid ticks in Japan: rapid species identification by 16S rRNA gene-targeted PCR analysis. Microbiol. Immunol. 40: 877-881.

Gern, L., U. E. Schaible, and M. M. Simon. 1993. Mode of inoculation of the Lyme disease agent Borrelia burgdorferi influences infection and immune responses in inbred strains of mice. J. Infect. Dis. 167: 971-975.

Gern, L., O. Rais, C. Capiau, P. Hauser, Y. Lobet, E. Simoen, P. Voet, and J. Pêtre. 1994. Immunization of mice by recombinant OspA preparations and protection against Borrelia burgdorferi infection induced by Ixodes ricinus tick bites. Immunol. Lett. 39: 249-258.

Gern, L., C. M. Hu, P. Voet, P. Hauser, and Y. Lobet. 1997. Immunization with a polyvalent OspA vaccine protects mice against Ixodes ricinus tick bites infected by Borrelia burgdorferi ss, Borrelia garinii, and Borrelia afzelii. Vaccine 15: 1551-1557.

Golde, W. T., T. R. Burkot, J. Piesman, M. C. Dolan, C. Capiau, P. Hauser, G. Dequesne, and Y. Lobet. 1995. The Lyme disease vaccine candidate outer surface protein A (OspA) in a formulation compatible with human use protects mice against natural tick transmission of $B$. burgdorferi. Vaccine 13: 435-441.

Hu, C. M., L. Gern, and A. Aeschlimann. 1992. Changes in the protein profile and antigenicity of different Borrelia burgdorferi strains after reintroduction to Ixodes ricinus ticks. Parasite Immunol. 14: 415-427.

Humair, P. F., N. Turrian, A. Aeschlimann, and L. Gern. 1993. Lxodes ricinus immatures on birds in a focus of Lyme Borreliosis. Folia. Parasitol. 40: 237-242.

Humair, P. F., O. Péter, R. Wallich, and L. Gern. 1995. Strain Variation of Lyme disease spirochetes isolated from Ixodes ricinus ticks and rodents collected in two endemic areas in Switzerland. J. Med. Entomol. 32: 433438.

Isogai, E., S. Tanaka, I. S. Braga III, C. Itakura, H. Isogai, K, Kimura, and N. Fujii. 1994. Experimental Borrelia garinii infection of Japanese quail. Infect. Immunol. 62: 35803582 .

Kurtenbach, K., A. Dizij, H. M. Seitz, G. Margos, S. E. Moter, M. D. Kramer, R. Wallich, U. E. Schaible, and M. M. Simon. 1994. Differential immune responses to Borrelia burgdorferi in European wild rodent species influence spirochete transmission to Ixodes ricinus (L.) (Acari: Ixodidae). Infect. Immunol. 62: 5342-5344.

Lane, R. S., J. Piesman, and W. Burgdorfer. 1991. Lyme Borreliosis: relation of its causative agent to its vectors and hosts in North America and Europe. Annu. Rev. Entomol. 36: 587-609.

Lovrich, S. D., S. M. Callister, L.C.L. Lim, and R. F. Schell. 1993. Seroprotective groups among isolates of Borelia burgdorferi. Infect. Immunol. 61: 4367-4374.

Magnarelli, L. A., K. C. Stafford III, and V. C. Bladen. 1992. Borrelia burgdorferi in Loodes dammini (Acari: Ixodidae) feeding on birds in Lyme, Connecticut, U.S.A. J. Zool. 70: 2322-2325.

Marconi, R. T., M. E. Konkel, and C. F. Garon. 1993. Variability of osp genes and gene products among species of 
Lyme disease spirochetes. Infect. Immunol. 61: 26112617.

Mather, T. N., M. L. Wilson, S. I. Moore, J. M. Ribeiro, and A. Spielman. 1989. Comparing the relative potential of rodents as reservoirs of the Lyme disease spirochete (Borrelia burgdorferi). Am. J. Epidemiol. 130: 143-150.

Mathiesen, J. H., J. H. Oliver, Jr., C. P. Kolbert, E. D. Tullson, B.J.B. Johnson, G. L. Campbell, P. D. Mitchell, K. D. Reed, S. R. Telford III, J. F. Anderson, R. S. Lane, and D. H. Persing. 1997. Genetic heterogeneity of Borrelia burgdorferi in the United States. J. Infect. Dis. 175: 98-107.

Maupin, G. O., K. L. Gage, J. Piesman, J. Montenieri, S. L. Sviat, L. VanderZanden, C. M. Happ, M. C. Dolan, and B.J.B. Johnson. 1994. Discovery of an enzootic cycle of Borrelia burgdorferi in Neotoma mexicana and Ixodes spinipalpis from northern Colorado, an area where Lyme disease is nonendemic. J. Infect. Dis. 170: 636-643.

Mbow, M. L., M. Christe, B. Rutti, and M. Brossard. 1994. Absence of acquired resistance to nymphal lxodes ricinus ticks in Balb/C mice developing cutaneous reactions. J. Parasitol. 80: 81-87.

Mehl, R., and T. Traavik. 1983. The tick Ixodes uriae (Acari: Ixodidae) in seabird colonies in Norway. Fauna Norv. Ser. B. 30: 94-107.

Nakao, M., and K. Miyamoto. 1995. Mixed infection of different Borrelia species among Apodemus speciosus mice in Hokkaido, Japan. J. Clin. Microbiol. 33: 490-492.

Nohlmans, L.M.K.E., R. De Boer, A.E.J.M. Van Den Bogaard, and C.F.A. Van Boven. 1995. Genotypic and phenotypic analysis of Borrelia burgdorferi isolates from the Netherlands. J. Clin. Microbiol. 33: 119-125.

Olsen B., D. C. Duffy, T.G.T. Jaenson, A. Gylfe, J. Bonnedahl, and S. Bergstrom. 1995. Transhemispheric exchange of Lyme disease spirochetes by seabirds. J. Clin. Microbiol. 33: $3270-3274$.

Péter, O., and A. G. Bretz. 1992. Polymorphism of outer surface proteins of Borrelia burgdorferi as a tool for classification. Zentralbl. Bakteriol. 277: 28-33.

Péter, O., A. G. Bretz, and D. Bee. 1995. Occurrence of different genospecies of Borrelia burgdorferi sensu lato in Ixodid ticks of Valais, Switzerland. Eur. J. Epidemiol. 11: 463-467.

Péter, O., A. G. Bretz, D. Postic, and E. Dayer. 1998. Association of distinct species of Borrelia burgdorferi sensu lato with neuroborreliosis in Switzerland. Clin. Microbiol. Infect. (in press).

Piesman, J. 1993. Standard system for infecting ticks (Acari: Ixodidae) with the Lyme disease spirochete, Borrelia burgdorferi. J. Med. Entomol. 30: 199-203.

Piesman, J., T. N. Mather, J. G. Donahue, J. Levine, J. D. Campbell, S. J. Karakachian, and A. Spielman. 1986. Comparative prevalence of Babesia microti and Borrelia burgdorferi in four populations of Ixodes dammini in eastern Massachusetts. Acta Trop. 43: 263-270.

Piesman, J., M. C. Dolan, M. E. Schriefer, and T. R. Burkot. 1996. Ability of experimentally infected chickens to in- fect ticks with the Lyme disease spirochete, Borrelia burdorferi. Am. J. Trop. Med. Hyg. 54: 294-298.

Pollack, R. J., S. R. Telford III, and A. Spielman. 1993. Standardization of medium for culturing Lyme disease spirochetes. J. Clin. Microbiol. 30: 1251-1255.

Postic, D., M. V. Assous, P.A.D. Grimont, and G. Baranton. 1994. Diversity of Borrelia burgdorferi sensu lato evidenced by restriction fragment length polymorphism of $r f(5 S)-r l(23 S)$ intergenic spacer amplicons. Int. J. Syst. Bacteriol. 44: 743-752.

Schaible, U. E., R. Wallich, M. D. Kramer, L. Gern, J. F. Anderson, C. Museteanu, and M. M. Simon. 1993. Immune sera to individual Borrelia burgdorferi isolates or recombinant OspA thereof protect SCID mice against infection with the homologous strains but only partially or not at all against those of different OspA/OspB genotypes. Vaccine 11: 1049-1054.

Schwan, T. G., J. Piesman, W. T. Golde, M. C. Dolan, and P. A. Rosa. 1995. Induction of an outer surface protein on Borrelia burgdorferi during tick feeding. Proc. Natl. Acad. Sci. U.S.A. 92: 2909-2913.

Sinsky, R. J., and J. Piesman. 1989. Ear punch biopsy method for detection and isolation of Borrelia burgdorferi from rodents. J. Clin. Microbiol. 27: 1723-1727.

Stafford, K. C., III, V. C. Bladen, and L. A. Magnarelli. 1995. Ticks (Acari: Ixodidae) infesting wild birds (Aves) and white footed mice in Lyme, Connecticut, U.S.A. J. Med. Entomol. 32: 453-466.

Strle, F., Y. Cheng, J. A. Nelson, M. M. Picken, J. K. Bouseman, and R. N. Picken. 1995. Infection rate of Ixodes ricinus ticks with Borrelia afzelii, Borrelia garinii, and Borrelia burgdorferi sensu stricto in Slovenia. Eur. J. Clin. Microbiol. Infect. Dis. 14: 994-1001.

Strle, F., and M. Stantic-Pavlinic. 1996. Lyme disease in Europe. N. Engl. J. Med. 334: 803.

Takada, N., F. Ishiguro, H. Iida, Y. Yano, and H. Fujita. 1994. Prevalence of Lyme Borrelia in ticks, especially Ixodes persulcatus (Acari: Ixodidae), in central and western Japan. J. Med. Entomol. 31: 474-478.

Telford, S. R., III, J. E. Dawson, P. Katavolos, C. K. Warner, C. P. Kolbert, and D. H. Persing. 1996. Perpetuation of the agent of human granulocytic ehrlichiosis in a deer tick-rodent cycle. Proc. Natl. Acad. Sci. U.S.A. 93: 62096214.

Wikel, S. K., R. N. Ramachandra, D. K. Bergman, T. R. Burkot, and J. Piesman. 1997. Infestation with pathogen-free nymphs of the tick Ixodes scapularis induces host resistance to transmission of Borrelia burgdorferi by ticks. Infect. Immunol. 65: 335-338.

Wilske, B., V. Preac-Mursic, B. Schierz, R. Kuhbeck, A. G. Barbour, and M. Kramer. 1988. Antigenic variability of Borrelia burgdorferi. Ann. N.Y. Acad. Sci. 539: 126-131. Receiv
1998.

Received for publication 15 July 1997; accepted 18 February 